Editorial

\title{
Large social housing estates: From stigma to demolition?
}

FRANK WASSENBERG

OTB Research Institute for Housing, Urban and Mobility Studies, Delft University of Technology, P.O. Box 5030, 2600 GA Delft, The Netherlands (Tel.: +31-15-2784461; Fax:+31-15-2783450; E-mail: wassenberg@otb.tudelft.nl)

\section{Stigma and large housing estates}

It is curious that the most frequently reviewed and well thought-out large housing estates are now the areas with the worst image. In these areas the high expectations of the planners were not realized, as demonstrated by the deplorable image of some estates. Image is an important factor of a neighbourhood's popularity, affecting its position in the local or regional neighbourhood hierarchy. Many studies and reports about problematic areas indicate that a negative image - a stigma, see Section 3 - is one of the aspects of urban decay. However, far less is known about the specific role of image and stigma in the development of housing estates.

This special issue is an attempt to fill that gap. The aim of this issue is to analyse the relation between large-scale housing estates and negative territorial images. It shows how images are experienced and whose images are concerned. It differentiates between internal and external images and presents examples of how policy-makers deal with stigmatised housing areas. A negative image is both a result of and a cause for further decay. In a spiral of decay, stigma plays a distinct role, exacerbating the problems that already exist. The papers in this special issue concentrate on the image factor, though without ignoring the fact that serious problems are often found in these areas.

The residualisation or marginalisation of social housing leads to deprived neighbourhoods where socioeconomically disadvantaged tenants are being concentrated. These areas increasingly take on a problematic reputation. The residents are socially stigmatised merely for living in a stigmatised area. Some papers in this issue go into the topic of social exclusion. 
Large housing estates, which were built in the postwar decades when chronic housing shortages determined the political agendas, are an important part of present urban renewal efforts in all West-European countries. Nowadays renewal is a complex and integral process embracing all kinds of measures and strategies. However, hardly any attention is being paid to possibilities to influence the image - i.e., to image renewal - or to the way in which an improved image influences the success of an urban renewal process.

\section{Large housing estates: Optimism and disappointment}

There is something intriguing about large housing estates. At the time they were developed, large housing estates were the product of idealistic thoughts, futuristic views and great expectations. The 1960s was the heyday of Utopian thinking; the prevailing view was that planners could make and shape society. Those were the days of putting a man on the moon, of invaders from Mars, Star Trek and the Thunderbirds. Inner cities were rebuilt to make way for motorways, parking garages, tower blocks and shopping facilities. In the field of housing, the high-rise estates of the 1960s and early 1970s were literally highlights of modern planning. In most Western countries, a significant proportion of these dwellings were rental apartments, often in the social sector. They formed an attractive alternative to the narrow and stuffy inner-city flats. Large housing estates were supposed to provide healthy housing, with 'light, air and space'. The CIAM movement of modern architects (Congrés Internationaux d'Architecture Moderne), with famous names like Le Corbusier, Walter Gropius and Mart Stam, led the way. According to these principles millions of houses were built all across Europe and the rest of the world. In fact, most of the neighbourhoods in the post World War II generation are heavily influenced by CIAM ideas. Le Corbusier and his colleagues of the CIAM movement were the most influential architects of the 20th century, although Le Corbusier's actual production was rather low. Turkington et al. (2004) give seven reasons why high-rise blocks were developed and which great expectations existed. After a more or less comparable start, high-rise living subsequently developed in different ways. The authors calculate that in 15 selected European countries, about one out of every seven dwellings was built in high-rise blocks, an average that is boosted by practices in Eastern and Southern Europe.

Considering their idealistic and Utopian foundations, it is remarkable that these well thought-out areas have so many problems. Not all 


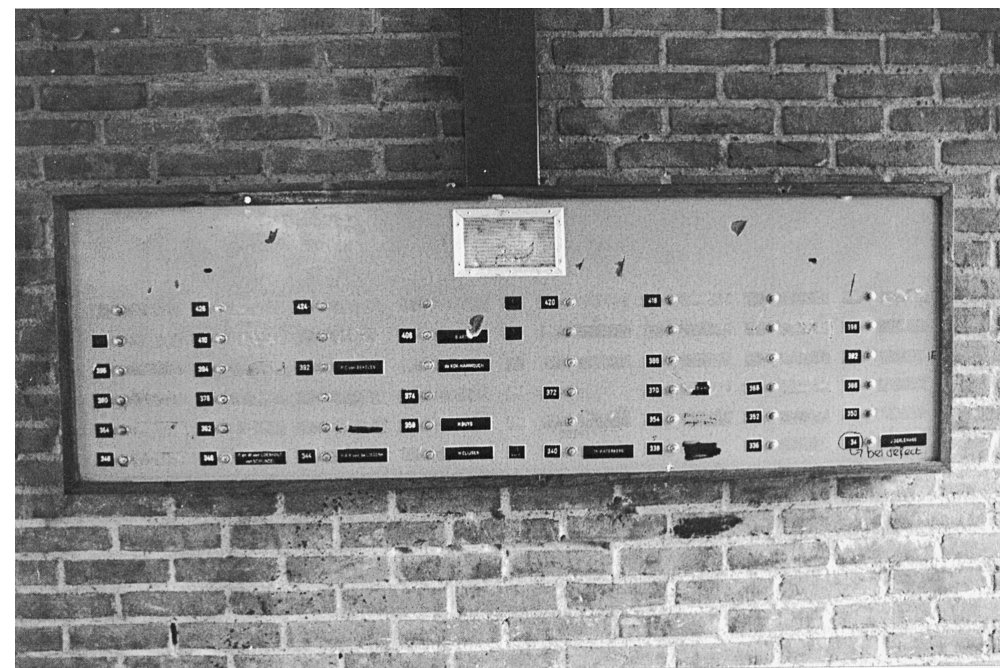

Photo 1. Vandalized and empty bell boards make a negative impression on visitors (photo: F.Wassenberg).

large housing estates are problematic, but in many countries many problematic areas are concentrated in large housing estates. Problems express themselves as low demand, vacancies, high turnover rates, a problematic exploitation, a lack of knowledge of the area and, on top of that, a stigma.

\section{On stigma}

In this special issue of the journal, the similar terms image, reputation and status are used in a neutral sense. An image, a reputation or a status of an area can be both positive and negative; as such, these are relative notions. A stigma, on the contrary, has only a negative connotation. It is associated with shame and disgrace, with the uncomfortable and unacceptable: all negative things. An area with a negative image has a stigma. In this issue, the term stigma denotes a negative image or reputation, and we use these terms in turn.

Identity is a related concept. In a pioneering study, Kevin Lynch (1960) worked out how people experience urban spaces and how the appearance of an urban area gives meaning to identity. Sluis has developed this concept further, calling identity the way in which different spatial elements in the city, like streets and blocks of houses, differ from 
each other. The wider the differences and the more landmarks or distinctions individuals experience, the more 'imageability', in Lynch's words, an area possesses. This mental aspect of an urban environment contributes directly to individuals' psychological well-being (Sluis, 2003).

Identity reflects the specific characteristics of a neighbourhood. One of the characteristics of the postwar proliferation of large housing estates is that these areas are not differentiated enough - some say not at all - and are lacking in identity and imageability. Many of these neighbourhoods look alike, especially in Eastern Europe; "When you have seen one estate, you have seen them all", according to Tsenkova (2000). In the West, according to policy-makers, the large-scale neighbourhoods need more variation, as diversity makes for quality. Neighbourhoods need an identity of their own.

It is easy to find examples of areas that carry a stigma, a bad image. Just open a local newspaper, and any local resident can point out negative events in certain areas, especially those on the other side of town. Table 1 gives some examples of the external conceptualisation of a particular area and the negative impacts of its stigma.

The examples in Table 1 are not listed in a random sequence. On top we see the more general examples, as experienced by the wider public. Going down the table we see examples that are more hidden expressions of a stigma, or manifestations that only are observed by some people or by persons with more specific knowledge. Obvious examples of imagebuilding are television programmes showing the misery of the area and photographs and articles in the newspaper, etc. Some researchers just

Table 1. Examples and consequences of stigma in certain neighbourhoods

Programmes or articles about the area focussing on crime, drug abuse, pollution, etc. Programmes or articles about crime, drug abuse, pollution, etc. using the area as a case Visible pollution, graffiti, vandalism, drug addicts hanging around, etc.

Vacant houses, empty shops

Poor schools

Friends, relatives and colleagues are reluctant to visit

Services won't deliver, taxis won't come to the area

Shortages of doctors, teachers, etc.

Discrimination on labour market

Higher insurance premiums; credit and financial services are denied

Advertisements for easily available houses

Property values lag behind 
count the reports in the papers to follow the news coverage about an area. Pollution, vacant houses or certain characteristics of the residents can be observed by simply walking around. Friends who are unwilling to visit, financial services being refused or a perceived discrimination on the labour market - these are things people may experience only after a while. Lagging property values or concentrations of advertisements for available properties are only visible to experts in the field. All these situations contribute to the creation of a stigma.

According to Dean and Hastings, it is not appropriate to refer to the image of an estate. Rather they prefer to speak of fractured images (Dean and Hastings, 2000, p. 13). Individuals emphasise different aspects of the estate and perceive it differently, depending on their own characteristics and experiences. Insiders within the area (inhabitants, daily workers) may have a different image than persons from outside the area. These images are called internal and external images or reputations, and both kinds are related (Suttles, 1972; Hortulanus, 1995). The internal reputation is based on physical and social characteristics of the neighbourhood. The external reputation, which is formed by outsiders, is often based on simple stereotypes, especially when the image is negative. Areas are compared to one another and assigned a place in the urban neighbourhood hierarchy. The reputations of the good and bad areas, as represented by their image, are mostly shaped by persons from outside the area. Forrest and Kearns write about "residential identities that are embedded in a strongly comparative psychological landscape in which each neighbourhood is known primarily as a counterpart of some of the others (...) Neighbourhoods seem to acquire their identity through an on-going commentary between themselves and this continuous dialogue between different groups and agencies shapes the cognitive map of the city and establishes good and bad reputations" (Forrest and Kearns, 2001, p. 2135).

The inhabitants are being influenced by negative external reputations, although maybe not as clearly and directly as Forrest and Kearns suggest. In some estates the inhabitants do have big problems, namely with liveability, pollution and safety, and these problems only confirm the external image. In other estates the problems mainly exist in the minds of outsiders, not in the experience of the inhabitants. People live well there, but sometimes they have to cope with negative judgements about their area.

Stigmatisation of areas is part of a discourse about social exclusion, the underclass concept and the residualisation of the public housing sector. Both the Australian and the Belgian papers in this issue focus on 
this discourse. They go into the discussion on the growing Stigmatisation of public housing. They also consider the question of whether marginalised public estates form a last resort for the most excluded tenants or are the cause of the problems: exclusion through housing or exclusion from housing. Stigmatisation also plays an important role in discussions among social scientists about the concept of the ghetto. Recently, the French-American sociologist Loïc Wacquant made an analytical concept out of the term ghetto. He identified four features of a ghetto: stigma, constraint, spatial confinement and institutional encasement (Wacquant, forthcoming). All ghettos do have a stigma, but not all stigmatised areas are ghettos.

Discussions about images have an ambiguous character. On the one hand, there is a large body of literature describing problematic estates where stigma is an issue. On the other hand, there is hardly any specific literature about the role of image in particular neighbourhoods. In a contribution to this issue, Hastings states that within the housing and regeneration literature, there is a strong emphasis on behavioural and cultural explanations for the problem of stigma. Yet she points out that within this literature, there are actually few detailed studies of the phenomenon of stigma itself. Earlier, Hastings did research on how the factor of image is dealt with in renewal projects. She found that it is difficult to get rid of a negative image in three British housing estates that are being renewed, and it takes a great deal of effort (Dean and Hastings, 2000). Buys concluded earlier that little is known about the factor of status (or reputation or image). A negative status of a neighbourhood may have a strong impact on the local housing market position. His conclusion is based on findings from an area in Tilburg, the Netherlands, where intensive social management was not enough to change the local stigma. Hardly any literature exists on status and how it can be influenced (i.e., improved) (Buys, 1997, p. 95). There are many studies and reports about problematic areas in which a negative reputation is one of the factors but not about the specific role of stigma.

\section{Urban renewal and image renewal}

A stigmatised public opinion, once established, is a result of all the problems that are present in an area. In the literature on the decay of estates, a worsening reputation is often mentioned as the result of all kinds of serious problems. The media are eager to confirm these stigmas. In this way, a bad image can cause further decay. Inhabitants are 
confronted with the sequence of factors listed in Table 1, and outsiders will think twice about going into the area. The decline of a problematic estate is often described as a vicious circle, a stigma being one of the factors pulling it downward.

In such a situation, renewal of a neighbourhood is necessary. Urban renewal is an important policy all across Europe. More and more, the large housing estates of the 1960s constitute a major share of this renewal burden. The measures may be housing oriented - calling for refurbishing, modernising or demolition of old estates and building new types of houses that people prefer. The measures may also call for improving the immediate setting, the semi-public spaces like entries, halls, storage areas and corridors. Or they may be aimed at the wider surroundings and involve upgrading the green space and amenities like schools and shops. Moreover, measures may be directed toward the residents themselves, who often suffer from a range of personal problems like inadequate schooling, unemployment or financial problems. Measures may also be oriented toward the way people live together, stimulating integration, mitigating nuisance and promoting involvement. Or an integral approach could be taken, pursuing all of these aims.

Large housing estates, as areas where problems tend to concentrate, are being renewed all over Europe, but it is important to consider whether their image will improve as well. Image renewal is only effective when the reality is changing as well. In practice, the image of a neighbourhood, and especially a negative one, is hardly treated as a factor. In most renewal strategies, image-building is not explicitly mentioned. There are possibilities to actively promote the image of a neglected area. What often happens is that large amounts of money are put into various measures, mostly for physical improvement. Various social and economic measures are taken at a lower scale, but efforts to promote an area are almost entirely neglected, especially after the euphoria of the renewal programme has faded away. The old negative reputation proves to be persistent, and after some years everything looks the same as before.

Improving the image of an area is a long-lasting process. In problematic areas image promotion always needs to be combined with (a range of) other measures. Even when the actual situation is being improved, a stigma can last for many years, maybe even a lifetime. Moreover, it takes a long time to remove a stigma once it has taken root - if possible at all - even when a large renewal programme is taking place. Atkinson and Kintrea (2000) and Beekman et al. (2001) confirm 


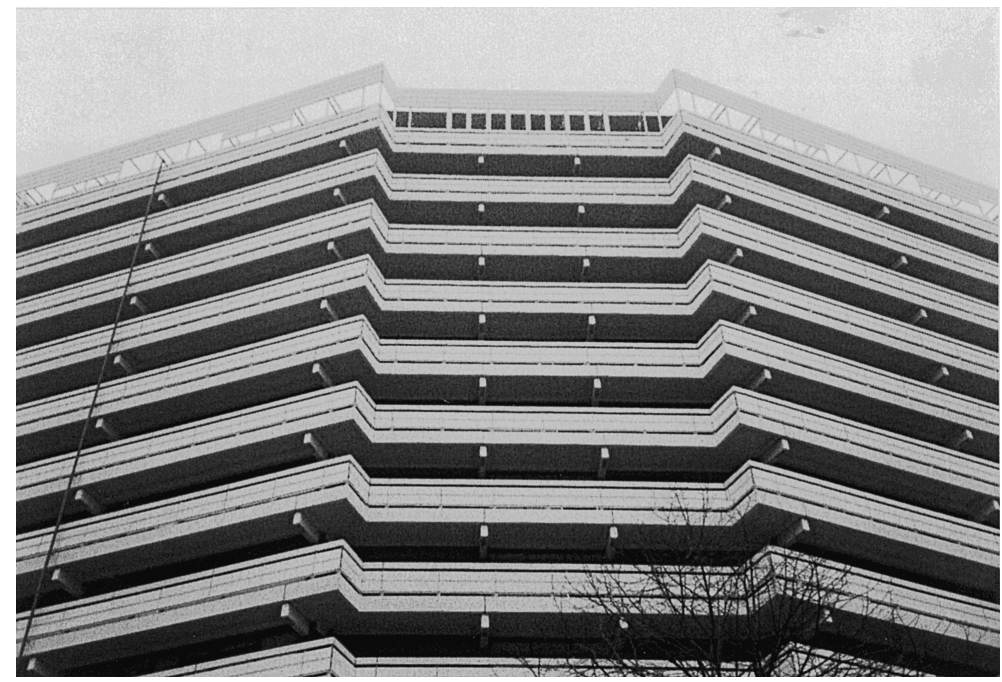

Photo 2. High-rise: massive, impressive, and dominating, but also impersonal, anonymous and monotonous.

this point, in the light of research in areas that have been regenerated through changes in housing types and tenures. The neighbourhood may change more quickly than its image. Sometimes it is easier to change the area itself than to change its image. Image-building may be one way to move forward, at least to some extent, in this complicated process.

\section{Editorial: Contributions to this issue}

This special issue deals with the relation between large housing estates and image-building. Each paper concentrates on this relation but places it in the context of a specific topic. All papers treat stigmatised large housing estates that are being neglected, renewed, refurbished or demolished and replaced. Altogether, these papers describe the range of relations between a deprived area, the image it has and the way policymakers are dealing with it.

In the first paper, Annette Hastings (from the UK) elaborates on the causes of stigma, distinguishing pathological, structural and area effects. Furthermore, she concentrates on the actors behind a stigma. The focus is on people and their positions, actors experiencing, making or dealing with images. Hastings differentiates within the groups of internal and external actors, distinguishing normalisers and pathologisers. Her aim is 
to understand why deprived estates remain stigmatised, even after processes of regeneration have started. While many actors are involved in image-building, few are actively involved in challenging the negative images.

In the second paper, Kathy Arthurson (from Australia) connects the marginalisation of the social sector in her country with the wider debate about social exclusion. She asks whether people are excluded from decent housing or if people are excluded through housing, excluded because they live somewhere. The paper concentrates on the small and residualising position of the social rented housing sector. In three comparable cases, opposite strategies - ranging from holistic approaches to demolition - were followed to get rid of stigmatised areas.

Frank Wassenberg (from the Netherlands) expands on the topic of internal and external images. A negative external image accelerates the development of internal problems and lowers the reputation of a neighbourhood. He considers the extent to which urban renewal leads to a better image and in what way image renewal is possible. Wassenberg states that images of neighbourhoods could be more actively promoted, using image-building as a supplementary strategy alongside other renewal activities. He presents a framework in which to position neighbourhoods according to insider and outsider images. The respective positions make it possible to envisage a strategy for image promotion, dependent on local circumstances.

Pascal De Decker and Isabelle Pannecoucke (from Belgium) launch the notion of the incapable tenant in the social housing sector. They concentrate on the contradiction between two images: on the one hand, the external image of stigmatised tenants living in ghettos amidst loads of problems and stereotyped by the media; on the other hand, the internal images of the tenants themselves, who can cope with the situation and are rather satisfied. The authors also mention the role that politicians play in marginalising the social sector in Belgium. This process has been going on for over ten years, leading to a stigmatisation of large housing estates, which are the neighbourhoods where the social rented sector is concentrated.

The last paper is by Ingar Bratbakk and Thorbjorn Hansen (from Norway). Even in one of the wealthiest countries on the continent, problems are appearing in large housing estates. Compared with other countries, Norway's problems are moderate, but this case demonstrates that every housing situation has to be considered within its own local or regional context. A stigmatised area is low in the regional housing hierarchy, no matter which country it is in. This makes local or regional 
situations in different countries comparable. Brattbakk and Hansen concentrate on the role of declining images in the process of decay. There is a growing polarisation between good and bad areas. An interesting aspect of the Norwegian situation is the positive role of housing cooperatives. Unlike other West-European countries, many large housing estates are not in the social rented sector but are owned by a cooperative in which an individual has a share. This arrangement offers perspectives for improvement.

\section{References}

Atkinson, R. and Kintrea, K. (2000) Owner Occupation, social mix and neighbourhood impacts, Policy and Politics, 28(1), 93-108.

Beekman, T., Lyons, F. and Scott, J. (2001) Improving the Understanding of the Influence of Owner Occupiers in Mixed Tenure Neighbourhoods (Report 89), Edinburgh, ODS Limited for Scottish Homes.

Buys, A. (1997) De Ideale Mix, [a study on population mix in neighbourhoods], RIGO, Amsterdam.

Dean, J. and Hastings, A. (2000), Challenging Images, Housing Estates, Stigma and Regeneration, The Policy Press, Bristol.

Forrest, R. and Kearns, A. (2001) Social Cohesion, social capital and the neighbourhood, Urban Studies, 38(12), 2125-2143.

Suttles, G.D. (1972) The Social Construction of Communities, The University of Chicago Press, Chicago/London.

Hortulanus, R.P. (1995) Stadsbuurten: Bewoners en Beheerders in Buurten met Uiteenlopende Reputaties (Inhabitants and managers in urban neighbourhoods with different reputations), VUGA, Den Haag.

Lynch, K. (1960) The Image of the City, MIT Press, Cambridge, MA.

Sluis, R.J. (2003) A Reassessment of Lynch's Conception of Meaning. In: Framing Indonesian Realities: Essays in Symbolic Anthropology in Honour of Reimar Schefold (Eds, Nas, P., Persoon, G. and Jaffe, R.), KITLV Press, Leiden, pp. 251274.

Tsenkova, S. (2000) Winds of Change: Transformation of Social Housing in CEE, keynote session ENHR Conference 2000, Gävle, Sweden.

Turkington, R. van Kempen, R. and Wassenberg, F. (2004) High-rise Housing in Europe, Current Trends and Future Prospects (HUPS 28), Delft University Press, Delft.

Wacquant, L. (forthcoming) What is a ghetto? Constructing a sociological concept, In: (Eds, Smelser, N. and Baltes, P.B.), International Encyclopedia of the Social and Behavioral Sciences, Pergamon Press, London. 